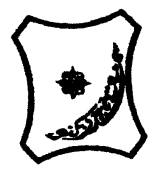

Bayero Journal of Pure and Applied Sciences, 11(1): 244 - 250

ISSN $2006-6996$

\title{
VALIDITY EVIDENCE OF ADAPTED HAUSA VERSION OF 8-ITEM MORISKY MEDICATION ADHERENCE SCALE IN PATIENTS WITH HYPERTENSION IN NORTH- WESTERN NIGERIA
}

\author{
${ }^{* 1}$ Labaran, K S, ${ }^{1}$ Mohammed, S, ${ }^{1}$ Maiha, B B, ${ }^{2}$ Giwa, A, ${ }^{1}$ Ma'aji, H U, ${ }^{3}$ Yusuf, H, and \\ ${ }^{4}$ Ibrahim, A W \\ ${ }^{1}$ Department of Clinical Pharmacy and Pharmacy Practice, Ahmadu Bello University, Zaria, Nigeria \\ ${ }^{2}$ Department of Clinical Pharmacy and Pharmacy Practice, University of Ilorin, Nigeria \\ ${ }^{3}$ Department of Clinical Pharmacy and Pharmacy Administration, University of Maiduguri, Nigeria \\ ${ }^{4}$ Mental Health Department, College of Medical Sciences, University of Maiduguri, Nigeria. \\ *Correspondence Author: +23436830072; kamilulabaran@yahoo.com
}

\begin{abstract}
Adherence to antihypertensive medication is the cornerstone for achieving hypertension control. Morisky Medication Adherence Scale (MMAS-8) is one of the most widely used selfreported medication adherence measures. The aim of this study was to examine the evidence of the validity of adapted Hausa MMAS-8 in assessing adherence among hypertensive patients in North-western Nigeria. In a longitudinal interventional study of individuals with hypertension, self-reported adherence to the antihypertensive drug treatment was measured using the Morisky Medication Adherence Scale-8. The internal consistency of the Morisky Medication Adherence Scale-8 with Cronbach's alpha, and factorial validity was assessed by identifying the underlying components using principal component analyses (PCA). A total of 130 individuals completed the study. Cronbach's alpha was 0.79 . Two components were identified. One component comprised six items: stopping medication when hypertension is under control, stopping when feeling hassled about sticking to the prescription. The second component comprised two other items that were all related to forgetfulness. A significant relationship between MMAS and diastolic blood pressure control $(t=2.2 ; p=.030),\left(x^{2}=6.6 ; p=.036\right)$ was found. The MMAS sensitivity and specificity, with positive and negative predictive values were $36 \%, 77 \%, 64 \%$, and $52 \%$ respectively. The results suggest that the adapted Hausa Morisky Medication Adherence Scale-8 is a two-dimensional scale assessing intentional (first component) and unintentional (second component) non-adherence to the antihypertensive drug treatment. The findings of this validation study indicate that the Hausa version of the MMAS is a reliable and valid measure of medication adherence among hypertensive patients in North-western Nigeria.
\end{abstract}

Keywords: Adherence; Hypertension; MMAS-8; Validation.

\section{INTRODUCTION}

Cardiovascular disease has been considered the leading cause of early disability and death worldwide, and hypertension is the most important preventable risk factor for the development of cardiovascular disease (de Oliveira-Filho et al., 2014; Irazola et al., 2016). Adherence to blood pressure lowering agents has been shown to be the cornerstone for achieving hypertension control, however, in the developing countries, the effective treatment of blood pressure among people taking antihypertensive medication, was below average, particularly due to non-adherence
(Abegaz et al., 2017; Irazola et al., 2016; Lloyd-Sherlock et al., 2014; Gwadry-Sridhar et al., 2013). Morisky medication adherence scale (MMAS-8) is one of the most widely used selfreported medication adherence measure, and different language versions have been in use worldwide, including the Hausa version (Bolarinwa et al., 2017; Zongo et al., 2016; Ibrahim et al., 2015; de Oliveira-Filho et al., 2014; Al-Qazaz et al., 2010; Sakthong et al., 2009). The aim of this study was to determine the psychometric properties of adapted Hausa MMAS-8 among hypertensive patients in Northwestern Nigeria. 


\section{MATERIALS AND METHODS}

\section{Study setting}

The study was conducted at Ahmadu Bello University Teaching Hospital Zaria, Northwestern Nigeria. The hospital has twenty clinical departments and provides twenty-four hour specialist medical care including stroke and heart conditions. Over 800 hypertensive outpatients were seen every month. Hypertensive patients were recruited from the Medical Outpatient Department during Cardiac Clinics that runs every Monday and Friday. Ethical clearance was obtained from Health Research Ethics Committee of Ahmadu Bello University Teaching Hospital, Zaria.

\section{Participants and study design}

This was an interventional longitudinal study conducted between February, 2016 and February, 2017. One hundred and thirty patients who met the inclusion criteria and consented to participate were randomly selected from the patients' waiting area prior to doctors' consultation. To be included in the study patient had to (1) be hypertensive and on medication (at least one drug), (2) be older than 18 years, (3) have active telephone line, (4) sign an informed consent, and be able to speak Hausa. At the start of the intervention, questionnaires were administered by a pharmacist and then administered again at the end of the intervention.

\section{The 8-item MMAS questionnaire}

This is a structured questionnaire that consist of 8 items designed to aid the identification of barriers to and behaviors associated with adherence to hypertensive medication (KorbSavoldelli et al., 2012; Jankowska-Polanska et al., 2016). All questions have dichotomised (yes/no) response except the eighth item, which has 5 -point Likert scale. Items 1 through 7 are scored as either ' 0 ' or ' 1 ' for 'yes' or 'no' response respectively, except for item 5 that has reversed scoring, and item 8 is scored as 1 , $0.75,0.5,0.25$ or 0 . Scores obtained are summed up to give total scale score, which range from 0 to 8 , with score of 8 reflecting high adherence, $6<8$ as moderate adherence, and $<6$ reflecting low adherence. The adapted Hausa version of the MMAS- 8 was originally used to measure adherence among patients with schizophrenia and bipolar disorder in Northeastern Nigeria by Ibrahim et al., (2015).

Data collection

The method for the collection of responses to the Hausa MMAS-8 was interviewer administered at baseline and at the end of the intervention. Patients' socio-demographic characteristics, medications and blood pressure values were extracted from the patients' records.

\section{Data analysis}

SPSS software v. 20 was used for the data analysis. Descriptive statistics was used to analyse categorical variables, which are presented in frequencies and percentages. Means and standard deviations were used to describe continuous variables. The $t$ - test or Mann Whitney $\mathrm{U}$ and ANOVA or Kruskal Wallis $\mathrm{H}$ were used for hypotheses testing for two or more groups of parametric and non-parametric data respectively. For the categorical variables chi square tests were used to test the null hypothesis. For the null hypothesis a $P$ value $\leq$ .05 was considered statistically significant. Internal consistency and test-retest reliability were assessed using Cronbach's alpha and intraclass correlation coefficients (ICCs), respectively. The criteria for accepting Cronbach's alpha ( $\geq 0.70$ ) was based on Nunally and Bernstein criteria (Korb-Savoldell et al., 2012). The criteria for interpretation of ICCS were based on Rosner's criteria (suggesting that ICC $<0.40=$ poor agreement, ICC $<0.75=$ fair to good agreement, ICC $\geq 0.75=$ excellent agreement (Sakthong et al., 2009). Principal component analysis with oblique rotation was used to determine the factorial validity. Scree plot test and parallel analysis were used to determine the number of factors to retain. Items with a loading $>.40$ on a factor were considered significant for a factor (Field, 2009).

\section{RESULTS}

Participant socio-demographic and adherence characteristics

The socio-demographic and adherence characteristics of the participants are presented in Table 1 . Of 130 participants, $61 \%$ (79) were females. The age range was (20 - 86 years, mean age $53.72 \pm 13$ ). The mean, median and mode adherence scores were $6.1 \pm 2.1,7.0$ and 8.0 respectively. For the adherence levels, $30.0 \%$ (39), $32.3 \%$ (42) and $37.7 \%$ (49) were low, moderate and high adherence respectively. There was no statistically significant difference in adherence between the socio-demographic categories $(P>.05)$. Statistically significant difference in adherence between the categories of hypertension duration and diastolic blood pressure control was found (Table 2).

\section{Reliability of scale score}

The internal-consistency reliability coefficient (Cronbach's alpha) for the MMAS was 0.79, which is above the acceptable value of 0.70 (Nunally and Bernstein, 2003); the test-retest reliability over a six weeks interval showed a fair intraclass correlation coefficient (ICC of $0.52(p<.001)$. 


\section{Known-group validity}

As shown in Table 2, a significant relationship between the MMAS and diastolic blood pressure control was obtained $(\mathrm{t}=2.2 ; p=.030),\left(\mathrm{x}^{2}=\right.$ 6.6; $p=.036$ ). As demonstrated in Table 3 , for the SBP control, $0.31,0.72,0.56$ and 0.47 were the sensitivity, specificity, positive and negative predictive values respectively. This sensitivity means that at baseline $31 \%$ of patients who had uncontrolled SBP reported low adherence, while the specificity indicates that $72 \%$ of patient who reported low-moderate adherence had controlled SBP. The positive predictive value means that $56 \%$ of patients with low adherence were poorly controlled whereas, the negative predictive value means that $47 \%$ of patients who were adherent had good control. However, for the DPB, the sensitivity, specificity, positive and negative predictive values were $0.36,0.77,0.64$, and 0.52 respectively. Thus, the MMAS has shown slightly more sensitivity and specificity for the DBP

\section{Construct validity}

A principal component analysis (PCA) was conducted with oblique rotation (Direct Oblimin). The Kaiser-Meyer-Olkin measure of sampling adequacy for the factor analysis was significantly adequate $\mathrm{KMO}=.75$ ('good' according to Field, 2009). Bartlett's test of sphericity $x^{2}(130)=402.38, p<.001$, indicated that correlations between items were significantly adequate for PCA. Two components had eigenvalues greater than 1 on Kaiser's criterion and in combination explained $58.8 \%$ of the total variance. The scree plot was unambiguous and showed inflexion that would justify retaining both components. Factor loadings on the 2 components after rotation are presented in Table 4. The items that cluster on component 1 suggest that it represent patients stopping their medication because of financial constraint and those items that cluster on component 2 suggest that it represent forgetfulness.

Table 1: Patients' Socio-demographic Characteristics and Scores on Adherence

\begin{tabular}{|c|c|c|c|c|c|c|c|c|c|}
\hline \multirow[t]{2}{*}{ Variable } & \multirow[t]{2}{*}{ n (\%) } & \multicolumn{3}{|l|}{ Score } & \multicolumn{5}{|c|}{ Level } \\
\hline & & Mean \pm SD & $\mathrm{F} / \mathrm{t} / \mathrm{U} / \mathrm{x}_{(2)}^{2}$ & $P$ & Low & Moderate & High & $x^{2}$ & $P$ \\
\hline \multicolumn{10}{|l|}{ Gender } \\
\hline Male & $51(39)$ & $6.35 \pm 1.9$ & \multirow[t]{2}{*}{1758.0} & \multirow[t]{2}{*}{.207} & 12 & 16 & 23 & \multirow[t]{2}{*}{2.42} & \multirow[t]{2}{*}{.299} \\
\hline Female & 79 (61) & $5.90 \pm 2.2$ & & & 27 & 26 & 26 & & \\
\hline \multicolumn{10}{|c|}{ Age categories } \\
\hline$\leq 40$ & $19(14)$ & $6.00 \pm 2.5$ & \multirow[t]{4}{*}{6.06} & \multirow[t]{4}{*}{.109} & 6 & 5 & 8 & \multirow[t]{4}{*}{11.49} & \multirow[t]{4}{*}{.074} \\
\hline $41-60$ & $76(60)$ & $5.78 \pm 2.5$ & & & 28 & 25 & 23 & & \\
\hline $61-80$ & $31(23)$ & $6.71 \pm 1.8$ & & & 4 & 12 & 15 & & \\
\hline $\begin{array}{l}>80 \\
\text { Religion }\end{array}$ & $4(3)$ & $7.25 \pm 1.5$ & & & 1 & 0 & 3 & & \\
\hline Muslim & $107(82)$ & $6.13 \pm 2.2$ & \multirow{3}{*}{1069.5} & \multirow{2}{*}{.311} & 31 & 33 & 43 & \multirow{3}{*}{1.61} & \multirow{2}{*}{.446} \\
\hline Christian & $23(18)$ & $5.83 \pm 1.9$ & & & 8 & 9 & 6 & & \\
\hline \multicolumn{8}{|c|}{ Marital status } & & \\
\hline Married & $118(91)$ & $6.05 \pm 2.1$ & \multirow[t]{5}{*}{1.57} & \multirow[t]{4}{*}{.665} & 36 & 39 & 43 & \multirow[t]{5}{*}{4.66} & \multirow[t]{4}{*}{.588} \\
\hline Single & 1 (1) & 8.00 & & & 0 & 0 & 1 & & \\
\hline Divorced & $3(2)$ & $6.00 \pm 3.5$ & & & 1 & 0 & 2 & & \\
\hline Widowed & $8(6)$ & $6.25 \pm 2.4$ & & & 2 & 3 & 3 & & \\
\hline \multicolumn{8}{|c|}{ Educational level } & & \\
\hline $\begin{array}{l}\text { No formal } \\
\text { education }\end{array}$ & $57(44)$ & $6.07 \pm 2.1$ & \multirow[t]{4}{*}{1.36} & \multirow[t]{4}{*}{.715} & 18 & 18 & 21 & \multirow[t]{4}{*}{2.89} & \multirow[t]{4}{*}{.821} \\
\hline Primary & $27(21)$ & $6.48 \pm 2.0$ & & & 5 & 11 & 11 & & \\
\hline Secondary & $13(10)$ & $5.85 \pm 2.4$ & & & 5 & 3 & 5 & & \\
\hline Tertiary & $33(25)$ & $5.85 \pm 2.2$ & & & 11 & 10 & 12 & & \\
\hline
\end{tabular}

$\mathrm{F}=$ ANOVA, $t=$ Students't,$U=$ Mann Whitney $\mathrm{U}, \mathrm{x}^{2}{ }_{(2)}=$ Kruskal Wallis $\mathrm{H}, \mathrm{x}^{2}=$ Chi square,$p=$ significance level $\leq .05, \mathrm{SD}=$ Standard Deviation, Low $=<6$, Moderate $=6-7$, High $=8$ 


\section{Special Conference Edition, November, 2018}

Table 2: Patients' Scores on Adherence, Hypertension Duration, and Blood Pressure Control

\begin{tabular}{|c|c|c|c|c|c|c|c|c|c|}
\hline \multirow[t]{2}{*}{ Variable } & \multirow[t]{2}{*}{ n (\%) } & \multicolumn{3}{|l|}{ Score } & \multicolumn{5}{|c|}{ Level } \\
\hline & & Mean \pm SD & $\mathrm{F} / \mathrm{t} / \mathrm{U} / \mathrm{x}_{(2)}^{L}$ & $P$ & Low & Moderate & High & $x^{2}$ & $P$ \\
\hline \multicolumn{10}{|c|}{ Hypertension duration (year) } \\
\hline$<5$ & $39(30)$ & $6.82 \pm 1.6$ & 13.54 & .095 & 5 & 16 & 18 & 30.77 & $.014^{*}$ \\
\hline $5-9$ & $14(11)$ & $5.57 \pm 2.7$ & & & 6 & 1 & 7 & & \\
\hline $10-14$ & $48(37)$ & $5.77 \pm 2.4$ & & & 17 & 13 & 18 & & \\
\hline $15-19$ & $11(8)$ & $5.45 \pm 2.0$ & & & 5 & 4 & 2 & & \\
\hline $20-24$ & $4(3)$ & $4.75 \pm 1.3$ & & & 3 & 1 & 0 & & \\
\hline $25-29$ & $6(5)$ & $6.33 \pm 2.2$ & & & 1 & 4 & 1 & & \\
\hline $30-34$ & $4(3)$ & $5.25 \pm 1.7$ & & & 2 & 2 & 0 & & \\
\hline $35-39$ & $1(1)$ & 8.00 & & & 0 & 0 & 1 & & \\
\hline$>39$ & $3(2)$ & $7.67 \pm 0.6$ & & & 0 & 1 & 2 & & \\
\hline \multicolumn{10}{|l|}{ SBP (mmHg) } \\
\hline Controlled & $60(45)$ & $6.37 \pm 2.0$ & 1735.5 & .083 & 17 & 15 & 27 & 3.50 & .174 \\
\hline Uncontrolled & 70 (55) & $5.83 \pm 2.2$ & & & 22 & 27 & 22 & & \\
\hline \multicolumn{10}{|l|}{ DBP $(\mathrm{mmHg})$} \\
\hline Controlled & $61(47)$ & $6.51 \pm 2.0$ & 2.19 & $.030^{*}$ & 14 & 17 & 30 & 6.63 & $.036^{*}$ \\
\hline Uncontrolled & $69(53)$ & $5.70 \pm 2.1$ & & & 25 & 25 & 19 & & \\
\hline
\end{tabular}

$\mathrm{SBP}=$ Systolic Blood Pressure, DBP = Diastolic Blood Pressure, $\mathrm{F}=$ ANOVA, $t=$ Students't, $U=$ Mann Whiteney $\mathrm{U}, \mathrm{x}^{2}{ }_{(2)}=\mathrm{Kruskall}$ Wallis $\mathrm{H}, \mathrm{x}^{2}=\mathrm{Chi}$ square, $p=$ significance level $\leq .05,{ }^{*}=$ Statistically Significant, SD $=$ Standard Deviation, Low $=<6$, Moderate $=6-7$, High $=8$

Table 3: Difference in Adherence and Associations with Blood Pressure Control

\begin{tabular}{|c|c|c|c|c|c|c|c|c|}
\hline \multirow[t]{3}{*}{ Adherence } & \multicolumn{4}{|c|}{ SBP $(\mathrm{mmHg})$} & \multicolumn{4}{|c|}{$\mathrm{DBP}(\mathrm{mmHg})$} \\
\hline & \multicolumn{2}{|c|}{ Controlled (\%) } & \multicolumn{2}{|c|}{ Uncontrolled (\%) } & \multicolumn{2}{|c|}{ Controlled (\%) } & \multicolumn{2}{|c|}{ Uncontrolled (\%) } \\
\hline & Baseline & Post-intv. & Baseline & Post-intv. & Baseline & Post-intv. & Baseline & Post-intv. \\
\hline Low & $17(28)$ & $13(13)$ & $22(31)$ & $3(10)$ & $14(23)$ & $9(11)$ & $25(36)$ & 7 (15) \\
\hline Moderate & $16(27)$ & $20(20)$ & $26(38)$ & $8(26)$ & $17(28)$ & $16(19)$ & $25(36)$ & $12(26)$ \\
\hline High & 27 (45) & $66(67)$ & $22(31)$ & $20(65)$ & 30 (49) & $58(70)$ & $19(28)$ & $28(60)$ \\
\hline Total (\%) & $60(46)$ & 99 (76) & $70(54)$ & $31(24)$ & 61 (47) & $83(64)$ & $69(53)$ & 47 (36) \\
\hline
\end{tabular}


Table 4: Summary of Exploratory Factor Analysis Results

\begin{tabular}{|c|c|c|c|c|}
\hline \multirow[t]{3}{*}{ Item } & \multicolumn{4}{|c|}{ Rotated factor loadings } \\
\hline & \multicolumn{2}{|c|}{ Intentional } & \multicolumn{2}{|c|}{ Unintentional } \\
\hline & Pattern & Structure & Pattern & Structure \\
\hline $\begin{array}{l}\text { Do you sometimes forget to take your high blood } \\
\text { pressure pills? }\end{array}$ & .26 & .48 & .69 & .73 \\
\hline $\begin{array}{l}\text { Over the past } 2 \text { weeks, were there any days when you } \\
\text { did not take your high blood pressure pills? }\end{array}$ & .42 & .54 & .38 & .51 \\
\hline $\begin{array}{l}\text { Have you ever cut back or stopped taking your } \\
\text { medication without telling your doctor? }\end{array}$ & .75 & .72 & -.08 & .15 \\
\hline $\begin{array}{l}\text { When you travel or leave home, do you sometimes } \\
\text { forget to bring along your high blood pressure } \\
\text { medication? }\end{array}$ & -.14 & .13 & .87 & .83 \\
\hline $\begin{array}{l}\text { Did you take your high blood pressure medication } \\
\text { yesterday? }\end{array}$ & .67 & .61 & -.21 & .01 \\
\hline $\begin{array}{l}\text { When you feel your blood pressure is under control, do } \\
\text { you sometimes stop taking your medication? }\end{array}$ & .63 & .69 & .16 & .36 \\
\hline $\begin{array}{l}\text { Taking medication every day is real inconvenience for } \\
\text { some people, do you ever feel hassled about sticking to } \\
\text { your high blood pressure treatment plan }\end{array}$ & .73 & .76 & .10 & .33 \\
\hline $\begin{array}{l}\text { How often do you have difficulty remembering to take } \\
\text { all your blood pressure medication? }\end{array}$ & .75 & .88 & .39 & .63 \\
\hline Eigenvalues & 3.65 & & 1.05 & \\
\hline$\%$ of variance & 45.58 & & 13.17 & \\
\hline
\end{tabular}

Factor loading $>.40$ appear in bold.

\section{DISCUSSION}

The main objective of this study was to examine the reliability and validity of the adapted translated Hausa version of the MMAS8 in hypertensive Hausa natives of northwestern Nigeria. This study showed that the translated Hausa MMAS-8 was two-dimensional, with good internal consistency reliability (Cronbach's alpha $=0.79$, which is $>0.70$ ), fairly reproducible $(I C C=0.52)$ and significantly associated with blood pressure control. The original MMAS-8 scale was tested by Morisky et al., (2008) on a sample of hypertensive patients, and was found to be one-dimensional with good reliability, predictive validity and sensitivity (Cronbach's alpha $=0.83$ ), and was significantly associated with blood pressure control $(P<.05)$ (Jankowska-Polanska et al., 2016). Similarly, the Polish version of the MMAS-8 that was validated among hypertensive subjects was reported to have good reliability coefficient (0.81), and was two-dimensional, with the two components explaining $59.9 \%$ of the total variance. These values were slightly above values obtained in this study, but consistently, the Polish version and the Hausa version had similar important components. Also, Ibrahim et al., (2015) has reported that the Hausa version of the MMAS-8 showed good reliability coefficient $(0.71)$ among patients with schizophrenia and bipolar disorder. However, the construct validity of the original Hausa version of the MMAS-8 scale was not reported. Other foreign versions of the MMAS- 8 have been reported to have lower reliability coefficient compared to the Hausa version. Reliability coefficient of $0.68,0.54,0.68,0.69$, 0.61 and 0.70 have been reported for the Brazilian-Portuguese, French, Malasian, Persian, Thai and Urdu versions respectively. For the known group validity, there was significant association between MMAS-8 and diastolic blood pressure control $\left(x^{2}=6.6 ; p=\right.$ .036). The sensitivity and specificity of the scale for both systolic and diastolic BP was comparable, however, the scale showed a poor sensitivity ( $\mathrm{SBP}=31 \%$; $\mathrm{DBP}=36 \%$ ), a specificity $(\mathrm{SBP}=72 \%$; $\mathrm{DBP}=77 \%)$, meaning that the scale was weak in detecting non-adherence. Morisky et al., (2008) showed that the original MMAS-8 had a sensitivity of $93 \%$ and a specificity of $53 \%$, meaning that the translated Hausa version had higher specificity but lower sensitivity than the original MMAS-8. The decreased sensitivity of the Hausa MMAS-8 may have been due to selfpresentational and recall biases, and the study participants may have answered untruthfully that they adhered to their antihypertensive medications, although they did not. Although patients' self-reported adherence is the most common method of assessment used in psychological research, it is subject to selfpresentational and recall biases. Patients may overestimate the extent of their adherence in an attempt to please the assessor or if they believe that admitting to non-adherence may result in adverse judgments or penalties. Moreover, patients' recall may be inaccurate. 
Special Conference Edition, November, 2018

Thus, because reports of non-adherence may be more accurate than reports of adherence, selfreport tends to underestimate the true extent of non-adherence by approximately $20 \%$. In contrast, self-report offers a convenient, "spot check" estimate of adherence behavior (Sakthong et al., 2009; Horne and Weinman, 1999). When the cut-off score for nonadherence was raised (non-adherence $=$ MMAS scores $\leq 7$ ), the sensitivity was increased to $69 \%$ and $72 \%$ for SBP and DBP respectively but the specificity decreased to $45 \%$ and $49 \%$ respectively. This indicated that the higher the sensitivity the lower the specificity and that the higher sensitivity had to be trade off against lower specificity. In clinical practice, healthcare providers are more interested in identifying patients who are uncontrolled and non-adherent than controlled and adherent patients; therefore, increasing the cut-off score of the scale can be a good option for solving its low sensitivity problem (Sakthong et al., 2009). The results of the principal component analyses showed that the adapted Hausa MMAS-8 has two latent traits; the intentional and unintentional non-adherence. Non-adherence has been described to be either intentional or unintentional and the scale could be measuring those two components (Horne et al., 2005). Thus, all of the items that load on the first factor's pattern and structure can be classified as causes of intentional non-adherence while the remaining two items that load on the second factor (pattern and structure) are all related to forgetfulness, which is a cause of unintentional non-adherence. This finding is consistent with that of Zongo et al., (2016), who reported that an adapted French MMAS-8

\section{REFERENCES}

Abegaz, T. M., Shehab, A., Gebreyohannes, E. A., Bhagavathula, A. S., Elnour, E. A. (2017). Nonadherence to antihypertensive drugs: A systematic review and meta-analysis. Medicine, 96(4): e5641

Al-Qazaz, H. K., Hassali, M. A., Shafie, A. A., Sulaiman, S. A., Sudram, S., Morisky, D. E. (2010). The eight-item Morisky Medication Adherence Scale MMAS: Translation and Validation of the Malaysian Version. Diabetes Research and Clinical Practice, 90: 216-221.

Bolarinwa, O. A., Bamgbola, O. A., Sanya, E. O., Kolo, P. M., Ameen, H.A., Durowade, K.A., Uthman,M. M. B., ... Morisky, D. E. (2017). Pattern and Explanatory Factors for Medication Adherence among Patients with Hypertension, Diabetes mellitus and their Comorbidity in a North Central State of Nigeria. International Journal was a two component scale, although the adapted French version was used among type 2 diabetic patients. The loading of six items (except cross-loadings) on the intentional nonadherence component of the Hausa MMAS-8 may be a clear indication of presence of practical barriers especially cost of medication to the participants' adherence. The result of our principal component analysis is inconsistent with that of the original MMAS-8 which has only one underlying component. The difference could be due to differences in the factor extraction methods used and/or in the methods used to retain the number of factors. However, in the original validity study, those methods were not reported (Zongo et al., 2016).

\section{CONCLUSION}

Reliability coefficient of the adapted Hausa MMAS8 was higher than the acceptable value of 0.70 . The Hausa MMAS-8 comprised two dimensions. One dimension was composed is of items related to intentional non-adherence, and the other dimension comprised items that measure unintentional non-adherence. Consequently, this study suggest that the Hausa MMAS-8 can help identify both intentional and unintentional nonadherence to antihypertensive drug therapy, and may therefore be beneficial for directing appropriate interventional strategies to improve adherence. Given the importance of accurately detecting medication non-adherence in clinical practice, future research should look at ways to improve this process. For example, studying the psychometric properties of other translated scales like the medication adherence rating scale (MARS) in order to identify the most reliable scale for our hypertensive patient population would be valuable.

of Public Health and Clinical Sciences, 4(4): 2289-7577.

de Oliveira-Filho, A. D., Morisky, D. E., Neves, S. J., Costa, F. A., de Lyra, D. P. Jr. (2014). The 8-item Morisky Medication Adherence Scale: validation of a Brazilian-Portuguese version in hypertensive adults. Research in Social and Administrative Pharmacy, 10: 554561.

Field, A. (2009). Discovering statistics using SPSS. Retrieved from http:// [Andy_Field]

_Discovering_Statistics_Using_SPSS_ (In (BookZZ.org).rar 
Gwadry-Sridhar, F. H., Manias, E., Lal, L., Salas, M., Hughes, D. A., RatzkiLeewing, A., Grubisic, M. (2013). Impact of Interventions on Medication Adherence and Blood Pressure Control in Patients with Essential Hypertension: A Systematic Review by the ISPOR Medication Adherence and Persistence Special Interest Group. Value in Health, 16: 863-871.

Horne, R., Weinman, J. (1999). Patients' Beliefs about Prescribed Medicines and their role in Adherence to Treatment in Chronic Physical Illness. Journal of Psychosomatic Research, 47(6): 555-567

Horne, R., Weinman, J., Baber, N., Elliot, R., Morgan, M. (2005). Concordance, adherenceand compliance in medicine taking. Retrieved from http://www.nets.nihr.ac.uk/_data/as sets/pdf_file/0007/81394/ES-08-1412076.pdf

Ibrahim, A.W., Pindar, S. K., Yerima, M. M., Rabbebe, I. B., Shehu, S., Garkuwa, H. A., Bashir, I. Y., Wakil, M. A., Yahya, S. J. (2015). Medication-related Factors of Non adherence among Patients with Schizophrenia and Bipolar Disorder: Outcome of a Cross-sectional Survey in Maiduguri, North-eastern Nigeria. Journal of Neuroscience and Behavioral Health, 7(5): 31-39. DOI: 10.5897/JNBH2015.0128

Irazola, V. E., Gutierrez, L., Bloomfield, G. S., Carrillo-Larco, R. M., Dorairaj, P., Gaziano, T., Levitt, N. S. (2016). Hypertension Prevalence, Awareness, Treatment, and Control in Selected Communities of Nine Low- and Middle Income Countries: Results from the NHLBI/UHG Network of Centers of Excellence for Chronic Diseases. Global Heart, 11(1): doi:10.1016/j.gheart.2015.12.008
Jankowska-Polańska, B., Uchmanowicz, I., Dudek, K., Mazur, G. (2016). Relationship between patients' knowledge and medication adherence among patients with hypertension. Patient Preference and Adherence, 10: 2437-2447

Korb-Savoldelli, V., Gillaizeau, F., Pouchot, J., Lenain, E., Postel-Vinay, N...Sabatier, B. (2012). Validation of a French version of the 8-item Morisky Medication Adherence Scale in Hypertensive Adults. Journal of Clinical Hypertension, 14: 429-434.

Lloyd-Sherlock, P., Beard, J., Minicuci, N., Ebrahim, S., Chatterji, S. (2014). Hypertension among older adults in low-and middle-income countries: prevalence, awareness and control. International Journal of Epidemiology, 43: 116-128. doi:10.1093/ije/dyt215

Morisky, D. E., Ang, A., Krousel-Wood, M., Ward, H. J. (2008). Predictive validity of a medication adherence measure in an outpatient setting. Journal of Clinical Hypertension, 10: 348-354.

Nunnally, J. C., \& Bernstein, I. H., (Eds.). (2003). Psychometric Theory, New York, NY: McGraw-Hill

Sakthong P, Chabunthom R, Charoenvisuthiwongs R. (2009).

Psychometric properties of the Thai version of the 8-item Morisky Medication Adherence Scale in patients with type 2 diabetes. Annals of Pharmacotherapy, 43: 950-957.

Zongo, A., Guénette, L., Moisan, J., Guillaumie, L., Lauzier, S., Grégoire, J. (2016). Revisiting the Internal Consistency and Factorial Validity of the 8-item Morisky Medication Adherence Scale. SAGE Open Medicine, 4(1): 1-7. 